\title{
The organ donation conundrum
}

A discrepancy exists between the demand for and the availability of solid organs for transplant. Barriers to organ donation can be encountered at 2 key points: (1) when trying to increase the number of people willing to become organ donors and registering their intent and (2) at the time of organ procurement. Several predictors of individual willingness to register as an organ donor are discussed, along with issues surrounding families' refusal of consent or failures in the hospital system to identify potential donors. Several countries have adopted presumed-consent policies and have seen a subsequent increase in donation rates. Research is needed to explore the effectiveness of approaches to overcome the barriers to individual registration and family consent, particularly in countries where presumed consent has not been and is not likely to be adopted. (Progress in Transplantation. 2012;22:312-316)

(C2012 NATCO, The Organization for Transplant Professionals doi: http://dx.doi.org/10.7182/pit2012216

\section{Conor Gilligan, PhD, Robert William Sanson- Fisher, PhD, Heidi Turon, PhD \\ University of Newcastle, Australia}

Corresponding author: Conor Gilligan, $\mathrm{PhD}$, Discipline of Health Behaviour Sciences, University of Newcastle, Level 4 West, HMRI Building, Callaghan NSW 2308, Australia (e-mail: conor.gilligan@newcastle.edu.au)

To purchase electronic or print reprints, contact:

The InnoVision Group

101 Columbia, Aliso Viejo, CA 92656

Phone (800) 899-1712 (ext 532) or

(949) 448-7370 (ext 532)

Fax (949) 362-2049

E-mail reprints@aacn.org
A discrepancy exists between the demand for and the availability of solid organs for transplant..$^{-3}$ This discrepancy represents a major public health concern, given the unnecessary loss of life associated with an inability to provide necessary organs. Change requires an increase in the number of registered donors, as well as the actual procurement of organs from potential donors. Organ donation is dependent on the existence of appropriate conditions at a series of steps from the individual, the family, the health professionals involved, and the policy context in which each of these factors exist. Several key barriers emerge at each of these steps, and effecting change could have synergistic benefits for rates of organ donation overall. The purpose of this commentary is to explore some of these issues in more depth and to identify possible future directions for efforts to tackle this problem.

\section{Barriers to Registration and Willingness to Donate}

Despite high levels of public support for organ donation, only a small proportion of individuals have registered an intention to donate or signed a donor card. For example, $77 \%$ of Australians have indicated that they are willing to become organ and tissue donors, ${ }^{4}$ but only $33 \%$ of eligible females and $30 \%$ of eligible males have formally registered their intent or consent to donate. ${ }^{5}$ Registration of consent appears to be an important strategy in increasing actual organ donation, as it has been suggested that a 5\% increase in the registration of consent for organ donation would translate into a $3 \%$ to $4 \%$ increase in actual organ donations. ${ }^{6}$

Differing results have been reported in relation to the individual-level determinants of registration and willingness to donate. A study with Dutch adolescents reported that religion and education had no impact, whereas negative outcome beliefs, anxiety, and social expectations (whether parents, friends, and partners would expect the person to register as a donor) were predictors of willingness to register as an organ donor.? In contrast, population-based data from the United States and Europe suggest that both general education levels and mother's education level had a positive influence on willingness to donate. ${ }^{6}$ Some studies ${ }^{8}$ have shown that religious beliefs positively influence an individual's desire to donate their organs, whereas other studies $^{9,10}$ have shown that strong religious beliefs can negatively influence attitudes toward organ donation. 
In the United States, African Americans, Hispanics, and Catholics are less likely to be registered as organ donors. ${ }^{6}$ It is hypothesized that, in some cases, these lower registration rates may result from a lack of trust in the medical system and fears about the respectful treatment of the body or about premature declaration of death. ${ }^{11}$ In Europe, individuals who report being familiar with the policies associated with the donation and transplant of human organs are more likely to donate. ${ }^{6}$ Other factors that influence the likelihood of becoming an organ donor include sex (females are more likely to donate) and political opinions (those with more liberal or left-wing political views are more likely to donate). ${ }^{6}$

In many countries, including Australia, families are required to give consent before organ donation takes place. Therefore it is important for individuals to communicate their wishes about organ donation to their loved ones. However, barriers to family discussion also exist and must be addressed in order to increase organ donation rates. Hyde and White ${ }^{12}$ report that an individual's perception about whether their family would agree with and support their decision has a substantial effect on their decision to discuss organ donation preferences. Exploration of the decision-making process led these authors to highlight the importance of focusing on behavioral and normative beliefs about donation and about the significance of communicating the donation decision to families.

\section{Barriers to Actual Donation and Family Consent}

The second major issue concerns family and hospital-related barriers at the time of actual organ procurement. In countries where the family must give consent in order for organ donation to proceed, consent rates are currently only about $60 \%{ }^{1.4}$ One factor consistently reported as a barrier to family consent is the lack of knowledge of the deceased person's wishes. Evidence suggests that families are much more likely to consent to organ donation if they know that the deceased had registered to donate, with $93 \%$ of Australians stating that they would uphold their loved one's wishes if they had knowledge of their wishes. ${ }^{4}$

Family consent or refusal is strongly linked with the involvement of health professionals and the practices of discussing donation with families. Several studies have examined the rate of family consent in the context of different request processes and timing of requests. In a systematic review Simpkin and colleagues ${ }^{13}$ found that the timing of the request, the approach of the requesting individual, and the setting in which the request is made have been reported as key modifiable factors associated with families' consent to donation. A comparison of donor and nondonor families showed that factors associated with consent included beliefs and attitudes about organ donation and transplantation, whether the family knew the deceased person's wishes about donation, and the family's satisfaction with the hospital care that their relative received. ${ }^{14}$

Some evidence suggests that families of potential organ donors receive inadequate information to make informed choices and their emotional needs are not consistently met. ${ }^{15}$ A US study reported 3 key factors that influenced the family's decision: allowing the family to understand and accept brain death before any discussion of organ donation, participation of the procurement coordinator in the request for consent, and making the request in a quiet, private place. ${ }^{16} \mathrm{~A}$ study in the United Kingdom also suggested that early, direct, and tacit communication regarding recovery prospects, assurances about respectful treatment of the decedent's body, and conducting these discussions in nonsurgical attire may support relatives in consenting to donation. ${ }^{17}$ Substantially higher family consent rates have been achieved when the discussion about organ donation is temporally separated from the explanation of the death. ${ }^{18,19}$

The skills and attitudes of staff making requests for donation consent have also been cited as a barrier to successful consent. The European Donor Hospital Education Program uses simulated family members and role playing to improve staff members' skills in grief response and the donation request..$^{20,21}$ Evaluations of the program have demonstrated improvements in staff self-efficacy and a decrease in the perceived difficulty of the donation discussion. ${ }^{20}$ However, increases in physicians' communication skills in breaking bad news and requesting donation were not maintained 6 months after the program. ${ }^{21}$

In a US study, researchers conducted a trial of changing the way that the families of patients who were registered as donors with the Department of Motor Vehicles (DMV) were approached. Rather than seeking the family's consent, representatives from the organ procurement organization asked families to honor the wishes of the patient, as registered with the DMV. This change led to an increase in consent from the families of DMV-registered patients from $80 \%$ to $100 \% .^{22}$

In a study ${ }^{23}$ in the United Kingdom, researchers compared collaborative requesting by the potential donor's clinician and a donor transplant coordinator in order to gain consent for organ donation with the requesting being done by the clinical team alone, and they found that collaborative requesting did not increase consent rates. Routine questioning of patients upon admission to hospital is reported to lead to the identification of potential donors, which may alleviate some of the difficulty associated with the discussion at the time of death..$^{24}$

In a study ${ }^{25}$ in the United States that used trained requestors as opposed to regional organ procurement officers, researchers found that despite the selection of staff who had experience in organ donation procedures 
and a strong personal belief in donation, the consent rates achieved by these individuals were lower than those achieved by the organ procurement officers. It was subsequently recommended that a multidisciplinary approach be taken to the consent process. ${ }^{25}$

System- or hospital-level barriers have also long acted as impediments to the procurement of organs. Failure to routinely report cases of brain death has been cited as a barrier to rates of organ donation internationally ${ }^{26,27}$ A study of the efficacy of donor teams in supporting the logistics (reporting and consent processes) of donation in Saudi Arabian hospitals led to an increase in reporting and subsequently, consent rates. ${ }^{26}$ Reluctance of clinicians to approach families about the issue, the skills of clinicians, and the facilities available all influence the rate of organ procurement occurring at major hospitals. ${ }^{28}$ A National Organ Donation Breakthrough Series Collaborative project was launched in the United States in 2003 to tackle some of these hospital-level components of the issue. The project also was focused on the consent process, timing, and the inclusion of minority population groups. Before the start of this project, annual growth in deceased donation was $2 \%$ to $4 \%$; in 2004 , after the collaborative had started, deceased donation increased by $11 \% .^{29}$

\section{The Full Picture}

An individual's decision to register or carry an organ donor card and the decision of the family to allow organ donation are 2 different decisions made under different circumstances, and the 2 decisions can be described by using different decision-making constructs. ${ }^{30}$ However, evidence suggests that these 2 types of decisions are linked,,$^{31,32}$ with a family's knowledge that the deceased person had carried a donor card playing an important role in decisions to donate. ${ }^{4}$ It has been suggested that the most important role for donor cards may be the stimulation of family discussion..$^{33}$ Extensive research conducted in Europe indicates that individuals are more likely to consent to the donation of their own organs than to the donation of a relative's organs. ${ }^{34,35}$ Both of these decisions are influenced by the policies surrounding donation, as well as the social climate that influences attitudes toward donation..$^{35,36}$

Several European Union countries have recently adopted policies of presumed consent in an effort to increase the availability of organs for transplantation. Exploration of the impact of these changes suggests that the legislation itself and the enforcement and awareness of the presumed-consent policies have led to an increase in willingness to donate. It is suggested that this willingness is associated with the acceptance of donation as ideology, or a "social norm." ${ }^{37}$ Rithalia and colleagues ${ }^{38}$ conducted a systematic review of presumed-consent systems and reported that the variation in organ donation rates is likely to be the result of a combination of legislation, availability of donors, transplantation system organization and infrastructure, wealth and investment in health care, as well as underlying public attitudes to and awareness of organ donation and transplantation. The relative importance of each of these factors, however, is not clear. ${ }^{38}$

The "Spanish model" involves a national transplantation organization that is centrally responsible for maintaining waiting lists, transport of organs, compiling statistics, research, and training. ${ }^{39}$ Spain is the world leader in organ donation, using a voluntary system based on altruism. ${ }^{40}$ The system was established to overcome difficulties of inadequately trained staff, unidentified donors, and a reluctance to approach grieving families ${ }^{39,40}$ The organization's management structure is designed to give transplant coordinators in each hospital responsibility for the implementation of processes and accountability for performance. This model has been associated with substantial increases in donation rates, a decrease in family refusal, and an increase in the average age of donors since the 1980s..$^{39}$ There has recently been some debate, however, about the cost of the donation system, with financial incentives for tissue donor detection teams, disproportionate salaries for transplant surgeons, and the cost of drugs for patients receiving transplants. ${ }^{41}$

\section{Overcoming the Barriers}

An unpublished systematic review conducted by the authors highlighted that although they make up only a small proportion of publications, several intervention studies have been conducted to address the shortage of donors. Some interventions have targeted the area of increasing registrations (or intentions to register) through changing knowledge, attitudes, or awareness. Other interventions have been focused on strategies to increase consent at the time of death, or have been focused on health professionals' behavior or families' attitudes toward donation. In July 2008, the Australian government launched a new measure "A world's best-practice approach to organ and tissue donation for Australia," which included \$134.6 million over 4 years to fund reforms. ${ }^{42}$ One of the components of the approach is an "ongoing, nationally coordinated community awareness and education program to increase knowledge about organ and tissue transplantation and build public confidence in Australia's donation for transplantation system." ${ }^{43}$ This acknowledges the need to "dispel the myths surrounding organ donation, motivate action, and encourage people to tell family of their wishes." ${ }^{43}$ To date, this has resulted in several awareness campaigns and the establishment of the DonateLife organization. 


\section{Social Norms}

It seems that improvements may result from tackling the issue early, within families and the community, before it arises in a highly emotional environment and under difficult circumstances such as in the hospital. Attempts to change normative beliefs and promote communication about organ donation and donation decisions may help to increase registration of consent by potential organ donors and to increase family consent at the time of death. Increasing the acceptance of organ donation and creating a norm of organ donor registration at a societal level is likely to have the most significant effect on actual donation. Although the efforts targeted toward health professionals and the manner in which they seek family consent are reported to influence consent rates, changes in clinical practices and behaviors of health professionals are rarely maintained in the long term. Increasing general awareness and acceptance of organ donation, however, is likely to facilitate the familial consent process at the time of death.

\section{Family Discussions}

One of the approaches used by DonateLife has been to encourage families to discuss organ donation. A campaign run during the 2010 Christmas holiday period was based on the finding that "Less than 1 in 5 Australians have had a memorable discussion with their loved ones about their donation wishes" and attempted to normalize organ donation as a topic of family conversation. ${ }^{4}$ Such a message has great potential to create a climate of general awareness and acceptance of organ donation. By putting organ donation alongside religious and political views as topics discussed among families, and about which individuals are generally aware of their families' and loved one's views, it will be possible to create a social norm of acceptance and to alleviate fears associated with organ donation.

\section{Alleviating Fears}

It will be critical to ensure that families have accurate information about the processes associated with organ donation to ensure that family discussions are well informed. Many of the studies cited in this review refer to unfounded perceptions about the way that individuals are treated in order to retrieve organs, a lack of understanding of the concept of brain death, and unclear interpretation of religious views toward donation. Widespread "myth-busting"-type campaigns may assist in clarifying misperceptions about procurement processes. Although awareness campaigns have traditionally presented positive stories from the perspective of transplant recipients and the families of donors, they have less often been focused on the common fears and negative concepts of donation. More directly targeting these negative concepts to alleviate fears may be an innovative and effective approach to assist with efforts to alter social acceptance.

\section{Encouraging Action}

The discrepancy between acceptance and actual registration represents one of the greatest challenges to increasing organ donation rates. It is essential that the social norms discussed earlier have registration (the carrying of a donor card or other form of formal acknowledgment of registration) as the accepted norm. It has been acknowledged that acceptance of organ donation does not necessarily translate into formal registration, and as such, it is this step that must be encouraged. Possible approaches to encouraging individuals to take action include providing convenient opportunities for individuals to sign up (self-serve touch-screen units at highly frequented places such as shopping centers) and simplifying the sign-up process. There is very limited evidence for successful efforts focused on this step, and as such this approach requires great attention in future research.

\section{Conclusions}

This review of the literature has led to the identification of 4 key elements that are expected to be effective foci for improvement efforts. Creating social norms of acceptance of organ donation, encouraging family discussions, alleviating fears, and enabling action are all likely to be important elements of successful efforts to increase organ donation rates. Limited evidence is available from intervention studies to guide marketing campaigns or other social norms efforts in this area. Well-controlled and empirically rigorous research targeting the key elements identified here is needed to explore the effectiveness of approaches to overcome the barriers to registration and consent.

\section{Financial Disclosures}

None reported.

References

1. NHS Blood and Transplant. Transplant Activity in the UK: Activity Report 2009/10. http://www.nhsbt.nhs.uk/downloads /pdfs/temp/report.pdf. Accessed January 1, 2012.

2. Australian and New Zealand Organ Donation Registry. ANZOD Registry Report 2010. http://www.anzdata.org.au /anzod/v1/AR-2010.html. Accessed January 1, 2012.

3. Wolfe RA, Roys EC, Merion RM. Trends in organ donation and transplantation in the United States, 1999-2008. Am J Transplant. 2010;10(4 pt 2):961-972.

4. DonateLife. Organ Donation Facts \& Statistics. http://www .donatelife.gov.au/Discover/Facts-and-Statistics.html. Accessed January 1, 2012.

5. Australian Organ Donor Register. AODR Statistics: Medicare Australia 2011. http://www.medicareaustralia.gov.au/provider /patients/aodr/stats.jsp. June 21, 2012.

6. Mocan N, Tekin E. The determinants of the willingness to donate an organ among young adults: evidence from the United States and the European Union. Soc Sci Med. 2007; 65(12):2527-2538. 
7. Reubsaet A, van den Borne B, Brug J, Pruyn J, van Hooff H. Determinants of the intention of Dutch adolescents to register as organ donors. Soc Sci Med. 2001;53(3):383-392.

8. Morgan SE, Harrison TR, Afifi WA, Long SD, Stephenson MT. In their own words: the reasons why people will (not) sign an organ donor card. Health Commun. 2008;23(1):23-33.

9. Bresnahan M, Lee SY, Smith SW, et al. A theory of planned behavior study of college students' intention to register as organ donors in Japan, Korea, and the United States. Health Commun. 2007;21(3):201-211.

10. Rumsey S, Hurford DP, Cole AK. Influence of knowledge and religiousness on attitudes toward organ donation. Transplant Proc. 2003;35(8):2845-2850.

11. Callender CO, Miles PV. Obstacles to organ donation in ethnic minorities. Pediatr Transplant. 2001;5(6):383-385.

12. Hyde MK, White KM. Young Australian adults' knowledge and beliefs about organ donation. Prog Transplant. 2007;17(3): 220-227.

13. Simpkin AL, Robertson LC, Barber VS, Young JD. Modifiable factors influencing relatives' decision to offer organ donation: systematic review. BMJ. 2009;338:b991.

14. DeJong W, Franz HG, Wolfe SM, et al. Requesting organ donation: an interview study of donor and nondonor families. Am J Crit Care. 1998;7(1):13-23.

15. Beaulieu D. Organ donation: the family's right to make an informed choice. J Neurosci Nurs. 1999;31(1):37-42.

16. Gortmaker SL, Beasley CL, Sheehy E, et al. Improving the request process to increase family consent for organ donation. J Transpl Coord. 1998;8(4):210-217.

17. Haddow G. Donor and nondonor families' accounts of communication and relations with healthcare professionals. Prog Transplant. 2004;14(1):41-48.

18. Garrison RN, Bentley FR, Raque GH, et al. There is an answer to the shortage of organ donors. Surg Gynecol Obstet. 1991; 173(5):391-396

19. Niles PA, Mattice BJ. The timing factor in the consent process. J Transpl Coord. 1996;6(2):84-87.

20. Blok GA, Morton J, Morley M, Kerckhoffs CC, Kootstra G, van der Vleuten $\mathrm{CP}$. Requesting organ donation: the case of self-efficacy - effects of the European Donor Hospital Education Programme (EDHEP). Adv Health Sci Educ Theory Pract. 2004;9(4):261-282.

21. Morton J, Blok GA, Reid C, van Dalen J, Morley M. The European Donor Hospital Education Programme (EDHEP): enhancing communication skills with bereaved relatives. Anaesth Intensive Care. 2000;28(2):184-190.

22. Christmas AB, Mallico EJ, Burris GW, Bogart TA, Norton $\mathrm{HJ}$, Sing RF. A paradigm shift in the approach to families for organ donation: honoring patients' wishes versus request for permission in patients with Department of Motor Vehicles donor designations. J Trauma. 2008;65(6):1507-1509; discussion 1509-1510.

23. ACRE Trial Collaborators. Effect of "collaborative requesting" on consent rate for organ donation: randomised controlled trial (ACRE trial). BMJ. 2009;339.

24. Essebag V, Cantarovich M, Crelinsten G. Routine advance directive and organ donation questioning on admission to hospital. Ann RColl Physicians Surg Can. 2002;35(4):225-231.

25. Bires MH. Comparison of consent rates between hospital-based designated requestors and organ procurement coordinators. $J$ Transpl Coord. 1999;9(3):177-180

26. Al-Sebayel MI, Al-Enazi AM, Al-Sofayan MS, et al. Improving organ donation in Central Saudi Arabia. Saudi Med J. 2004;25(10):1366-1368.

27. Singer P. Cadaveric organ donation in Israel: the facts and the perspectives. Ann Transplant. 1999;4(1):5-10.

28. Mathew TH, Chapman JR. Organ donation: a chance for Australia to do better. Med J Aust. 2006;185(5):245-246.

29. Marks WH, Wagner D, Pearson TC, et al. Organ donation and utilization, 1995-2004: entering the collaborative era. Am J Transplant. 2006;6(5 pt 2):1101-1110.

30. Horton RL, Horton PJ. A model of willingness to become a potential organ donor. Soc Sci Med. 1991;33(9):1037-1051.

31. Manninen DL, Evans RW. Public attitudes and behavior regarding organ donation. JAMA. 1985;253(21):3111-3115.

32. Prottas JM. Encouraging altruism: public attitudes and the marketing of organ donation. Milbank Mem Fund Q Health Soc. 1983;61(2):278-306

33. Callender CO. Organ donation in the black population: where do we go from here? Transplant Proc. 1987;19(2 suppl 2):36-40.

34. Siminoff LA, Gordon N, Hewlett J, Arnold RM. Factors influencing families' consent for donation of solid organs for transplantation. JAMA. 2001;286(1):71-77.

35. Mossialos E, Costa-Font J, Rudisill C. Does organ donation legislation affect individuals' willingness to donate their own or their relative's organs? Evidence from European Union survey data. BMC Health Serv Res. 2008;8:48.

36. Radecki CM, Jaccard J. Psychological aspects of organ donation: a critical review and synthesis of individual and next-ofkin donation decisions. Health Psychol. 1997;16(2):183-195.

37. Verheijde JL, Rady MY, McGregor JL, Friederich-Murray C. Enforcement of presumed-consent policy and willingness to donate organs as identified in the European Union Survey: the role of legislation in reinforcing ideology in pluralistic societies. Health Policy. 2009;90(1):26-31.

38. Rithalia A, McDaid C, Suekarran S, Myers L, Sowden A Impact of presumed consent for organ donation on donation rates: a systematic review. BMJ. 2009;338:a3162.

39. Miranda B, Canon J, Cuende N. The Spanish organizational structure for organ donation: Update. Transplant Rev. 2001; 15(1):33-45

40. Garcia Rada A. Spanish transplant model would save 20,000 lives a year in EU. BMJ. 2010;340:c1758

41. Verdu F, Frances F, Castello A. Spanish transplantation model. Don't forget economics. BMJ. 2010;340:c2520.

42. Roxon N, Rudd K. \$136.4 Million National Plan to Boost Organ Donation and Save Lives. 2008; http://www.health .gov.au/internet/ministers/publishing.nsf/Content/mr-yr08-nr -nr100.htm. Accessed January 1, 2012.

43. Australian Federal Government. A World's Best Practice Approach to Organ and Tissue Donation for Australia. Overview. Canberra, Australia: Department of Health and Aging; 2008. http://www.health.gov.au/internet/ministers /publishing.nsf/Content/4CEBB8750FC436F8CA25747A000 7 A1F2/\$File/080702\%20\%20a\%20world\%27s\%20best $\% 20$ practice $\% 20$ approach $\% 20$ to $\% 20$ organ $\% 20$ and $\% 20$ tissue $\% 20$ donaction $\% 20$ for $\% 20$ Australia\% 20 overview.pdf Accessed January 1, 2012. 
Copyright of Progress in Transplantation is the property of North American Transplant Coordinators Organization, Inc. (NATCO) and its content may not be copied or emailed to multiple sites or posted to a listserv without the copyright holder's express written permission. However, users may print, download, or email articles for individual use. 